\title{
Study of J-V Characteristics of Microcrystalline Silicon Solar Cell on The Structure of P-I-N Homojunction
}

\author{
Yuningtyas Nely Kusuma Dewi ${ }^{1}$, Endhah Purwandari ${ }^{2, a}$, Khoirul Anwar ${ }^{2}$, \\ Misto $^{2}$ \\ ${ }^{1}$ Department of Physics, Faculty of Science and Data Analytics, Institut Teknologi Sepuluh \\ Nopember, Surabaya 60111, East Java, Indonesia \\ ${ }^{2}$ Departmen of Physics, Faculty of Mathematics and Natural Sciences, Universitas Jember, \\ Jember 68121, East Java, Indonesia \\ aendhah.fmipa@unej.ac.id
}

\begin{abstract}
Microcrystalline silicon $(\mu \mathrm{c}-\mathrm{Si})$ is a silicon semiconductor material with a crystalline structure in the amorphous phase. Here, the transport phenomenon in this phase has been modeled to produce charge carrier distribution profile and current density-voltage characteristics. The calculations were obtained by solving Poisson and Continuity equations on crystal and amorphous materials which are modeled in one-dimensional $p-i-n$ homojunction, using finite element method. The simulation results of the charge carrier distribution profile show that the highest electron concentration in the n-layer of $10^{18}$ $\mathrm{cm}^{-1}$, and the highest hole concentration in the p-layer of $10^{18} \mathrm{~cm}^{-1}$. The result current density-voltage $(\mathrm{J}$ V) characteristics curve show that the open circuitt voltage of 0,6 volts and short-circuit current density of $26.4 \mathrm{~mA} / \mathrm{cm}$. The energy conversion efficiency of $9.02 \%$ with a fill factor of 0.569 .
\end{abstract}

Keywords: Silicon, solar cell, amorphous, microcrystalline, polycrystal, monocrystal, short circuit current density, open voltage

\section{Introduction}

A solar cell is a device that converts solar energy into electrical energy directly. Solar cells are made of semiconductor material from the result of covalent bonding between material elements. One example of semiconductor materials that have been applied as production materials for transistor electronic devices, diodes, and solar cells is silicon [1]. Silicon is one of the basic semiconductor materials of IV groups which is composed of atoms with a specific structure. As material from solar cell devices, silicon can be used to some structures, that is amorphous, microcrystal, polycrystal, and monocrystal.

Microcrystal silicon ( $\mu \mathrm{c}-\mathrm{Si}$ ) is a silicon semiconductor material with a crystalline structure in the amorphous phase [2]. In 2004, Klein et al. reported the results of experiments on the growth microcrystal silicon solar cell with Hot Wire Chemical Vapor Deposition (HWCVD) techniques with a conversion efficiency of $9.4 \%$, open-circuit voltage of $0.58 \mathrm{~V}$, and short circuit current density of $23.3 \mathrm{~mA} / \mathrm{cm}^{2}$ [3]. To support the research without a large cost, a simulation of hydrogenated microcrystal silicon $(\mu \mathrm{c}-\mathrm{Si}: \mathrm{H})$ solar cell which has been done by Lin et al. in 2013 used the Centaurus TCAD simulator [4]. That simulation conversion efficiency of $9.7 \%$, the open-circuit voltage of $0.523 \mathrm{~V}$, and short circuit current density of $26.8 \mathrm{~mA} / \mathrm{cm}^{2}$ [5].

The effect of i-layer thickness on the characteristics of current-voltage in $p$-i-n junction of silicon crystalline based solar cell has been reported by Herawati [5]. In 2016, Sholeha has modeled the transport phenomena in hydrogenated amorphous silicon (a-Si: $\mathrm{H}$ ) solar cell devices by 
modifying the Herawati's result [6]. In this study, a simulation of hydrogenated microcrystal silicon ( $\mu \mathrm{c}-\mathrm{Si}: \mathrm{H})$ solar cell on $\mathrm{p}-\mathrm{i}-\mathrm{n}$ homojunction structure has performed the charge carrier distribution profile and current density-voltage $(\mathrm{J}-\mathrm{V})$ characteristics by combining amorphous and crystalline material modeling. To find out the results of modeling the device of solar cell based on hydrogenated microcrystal silicon ( $\mu \mathrm{c}-\mathrm{Si}: \mathrm{H})$ on $\mathrm{p}-\mathrm{i}-\mathrm{n}$ homojunction structure, the finite element method had been applied. The finite element method is a method that can be used to modify according to the geometric structure simulated.

\section{Materials and Methods}

The geometry of the simulated solar cell device is in the form of a $p$-i-n junction. The thickness of layer $p$, layer $i$, and layer $n$ are $0.015 \mathrm{~m}, 0.550 \mathrm{~m}$, and $0.300 \mathrm{~m}$, respectively [6]. Figure 1 shows the geometry of solar cells in a one-dimensional structure.

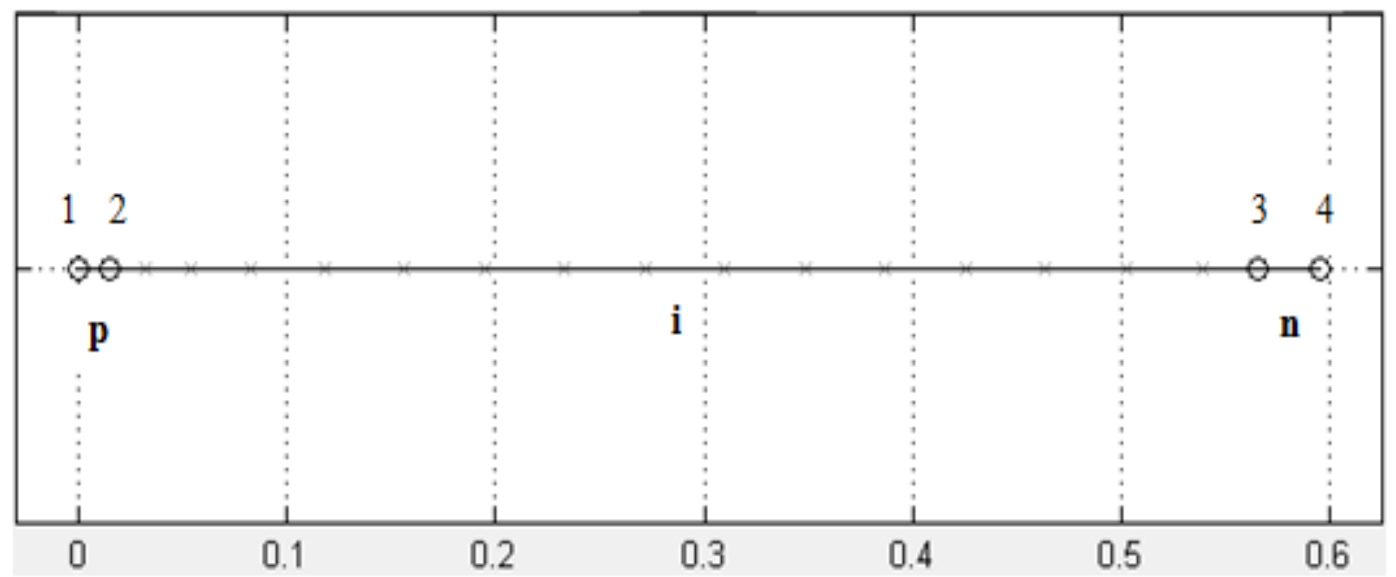

Figure 1. The geometry of hydrogenated microcrystalline silicon $(\mu \mathrm{c}-\mathrm{Si}: \mathrm{H})$ solar cell device on p-i-n junction 1D.

The first equation which used to determine the charge carrier distribution of solar cell based of hydrogenated microcrystal silicon ( $\mu \mathrm{c}-\mathrm{Si}: \mathrm{H})$ is the Poisson equation, as mention in equation 1 [7]. 


$$
\begin{aligned}
\nabla . \vec{\xi}=\frac{\epsilon}{q} \nabla^{2} \psi= & -\left(e^{\psi} u-e^{-\psi} v-N_{D}^{+}+N_{A}^{-}\right)+n_{i}\left(e^{\psi} u-e^{-\psi} v\right)-N_{D}^{+}+N_{A}^{-} \\
& -g_{D \min } E_{D}\left[\exp \left(\frac{E_{m c}-E_{c}}{E_{D}}\right)\left\{1-\left(\frac{2 e^{-\psi} v+c e^{\psi} u}{e^{-\psi} v+c e^{\psi} u}\right)\left(\frac{n_{i} e^{-\psi} v+c n_{i} e^{\psi} u}{c N_{c}}\right)^{-\frac{k T}{E_{D}}}\right\}\right. \\
& \left.+\exp \left(\frac{E_{m c}-E_{c}}{E_{D}}\right)\left\{\left(\frac{e^{-\psi} v}{e^{-\psi} v+c e^{\psi} u}\right)\left(\frac{n_{i} e^{-\psi} v+c n_{i} e^{\psi} u}{N_{v}}\right)^{\frac{k T}{E_{D}}}\right\}\right] \\
& +g_{A m i n} E_{A}\left[\exp \left(\frac{E_{v}-E_{m c}}{E_{A}}\right)\left\{\left(\frac{c e^{-\psi} v}{c e^{-\psi} v+e^{\psi} u}\right)\left(\frac{n_{i} c e^{-\psi} v+n_{i} e^{\psi} u}{c N_{v}}\right)^{-\frac{k T}{E_{A}}}-1\right\}\right. \\
& \left.+\exp \left(\frac{E_{c}-E_{m c}}{E_{A}}\right)\left\{\left(\frac{e^{-\psi} v}{c e^{-\psi} v+e^{\psi} u}\right)\left(\frac{n_{i} c e^{-\psi} v+n_{i} e^{\psi} u}{N_{c}}\right)^{\frac{k T}{E_{A}}}\right\}\right]
\end{aligned}
$$

The second equation which used the charge carrier distribution (electron-hole) is Continuity equation. Continuity equations for the charge carrier distribution of electron and hole, each written in equations 2 and equations 3 [7],

$$
\begin{aligned}
&-\nabla\left(\mu_{n} n_{i} e^{\psi} \nabla \psi+D_{n} n_{i} e^{\psi} u \nabla u\right)=\frac{n_{i}(u v-1)}{\tau_{p}\left(u e^{\psi}+1\right)+\tau_{n}\left(v e^{\psi}+1\right)} \\
&-\frac{G_{0} \alpha}{1-P}\left(e^{-\alpha x}+P e^{\alpha x}\right)+\frac{G_{0} \alpha(\lambda)}{1-P}\left(e^{-\alpha x}+P e^{\alpha x}\right) \\
&-n_{i}(u v \\
&-1) c v \sigma_{N}\left[( \frac { g _ { A m i n } E _ { A } } { e ^ { \psi } u + c e ^ { - \psi } v } ) \left\{\exp \left(\frac{E_{c}-E_{m c}}{E_{A}}\right)\left(\frac{n_{i}\left(e^{\psi} u+c e^{-\psi} v\right.}{N_{c}}\right)^{\frac{k T}{E_{A}}}\right.\right. \\
& \\
&\left.-\exp \left(\frac{E_{v}-E_{m c}}{E_{A}}\right)\left(\frac{n_{i}\left(e^{\psi} u+c e^{-\psi} v\right.}{c N_{v}}\right)^{-\frac{k T}{E_{A}}}\right\} \\
&+\frac{g_{D m i n} E_{D}}{c e^{\psi} u+e^{-\psi} v}\left\{\exp \left(\frac{E_{m c}-E_{c}}{E_{D}}\right)\left(\frac{n_{i}\left(c e^{\psi} u+e^{-\psi} v\right.}{N_{v}}\right)^{\frac{k T}{E_{D}}}\right. \\
&\left.-\exp \left(\frac{E_{m c}-E_{v}}{E_{D}}\right)\left(\frac{n_{i}\left(c e^{\psi} u+e^{-\psi} v\right.}{c N_{v}}\right)^{-\frac{k T}{E_{D}}}\right\}
\end{aligned}
$$




$$
\begin{aligned}
\nabla\left(\mu_{p} n_{i} e^{\psi} \nabla \psi+\right. & \left.D_{p} n_{i} e^{\psi} u \nabla u\right) \\
= & \frac{G_{0} \alpha}{1-P}\left(e^{-\alpha x}+P e^{\alpha x}\right)-\frac{n_{i}(u v-1)}{\tau_{p}\left(u e^{\psi}+1\right)+\tau_{n}\left(v e^{\psi}+1\right)}+\frac{G_{0} \alpha(\lambda)}{1-P}\left(e^{-\alpha x}+P e^{\alpha x}\right) \\
-n_{i}(u v & -1) c v \sigma_{N}\left[( \frac { g _ { A m i n } E _ { A } } { e ^ { \psi } u + c e ^ { - \psi } v } ) \left\{\exp \left(\frac{E_{c}-E_{m c}}{E_{A}}\right)\left(\frac{n_{i}\left(e^{\psi} u+c e^{-\psi} v\right.}{N_{c}}\right)^{\frac{k T}{E_{A}}}\right.\right. \\
& \left.-\exp \left(\frac{E_{v}-E_{m c}}{E_{A}}\right)\left(\frac{n_{i}\left(e^{\psi} u+c e^{-\psi} v\right.}{c N_{v}}\right)^{-\frac{k T}{E_{A}}}\right\} \\
& +\frac{g_{D m i n} E_{D}}{c e^{\psi} u+e^{-\psi_{v}}}\left\{\exp \left(\frac{E_{m c}-E_{c}}{E_{D}}\right)\left(\frac{n_{i}\left(c e^{\psi} u+e^{-\psi} v\right.}{N_{v}}\right)^{\frac{k T}{E_{D}}}\right. \\
& \left.-\exp \left(\frac{E_{m c}-E_{v}}{E_{D}}\right)\left(\frac{n_{i}\left(c e^{\psi} u+e^{-\psi} v\right.}{c N_{c}}\right)^{-\frac{k T}{E_{D}}}\right\}
\end{aligned}
$$

The variables used as input parameters based on Poisson and continuity equations are given in Table 1. The input parameters in the simulation of solar cell based on microcrystal silicon hydrogenated $(\mu \mathrm{c}-\mathrm{Si}: \mathrm{H})$ used c-Si and a-Si: $\mathrm{H}$ parameters.

Table 1. Input Parameter

\begin{tabular}{lr}
\hline \multicolumn{1}{c}{ Parameter } & \multicolumn{1}{c}{ Value } \\
\hline Electrical charge $(q)$ & $1.602 \times 10^{-19} \mathrm{C}[8]$ \\
Permittivity in vacuum $\left(\epsilon_{0}\right)$ & $305 \times 10^{-14} \mathrm{~F} / \mathrm{cm}[8]$ \\
Temperature $(T)$ & $300 \mathrm{~K}[8]$ \\
Boltzmann constant $(k)$ & $1.38 \times 10^{-23} \mathrm{~J} / \mathrm{K}$ \\
Relative Permittivity of material $\left(\epsilon_{r}\right)$ & $11.8 \mathrm{~F} / \mathrm{cm}[8]$ \\
Photon flux $(F)$ & $10^{-17} \mathrm{~cm}^{-2} \mathrm{~s}^{-1}[9]$ \\
Transmission factor $(P)$ & $0.71[7]$ \\
Light absorption coefficient $(\alpha)$ a-Si:H & $22222 \mathrm{~cm}^{-1}[10]$ \\
Light absorption coefficient $(\alpha) \mathrm{c}-\mathrm{Si}$ & $30000 \mathrm{~cm}^{-1}[11]$ \\
Charge carrier concentration $\left(n_{i}\right)$ & $1.46 \times 10^{10} \mathrm{~cm}^{-2}[8]$ \\
Donor concentration $\left(N_{D}\right)$ a-Si:H & $8.8 \times 10^{17} \mathrm{~cm}^{-3}[12]$ \\
Acceptor concentration $\left(N_{A}\right)$ a-Si:H & $1 \times 10^{17} \mathrm{~cm}^{-3}[12]$ \\
Donor concentration $\left(N_{D}\right) \mathrm{C}-\mathrm{Si}$ & $8 \times 10^{17} \mathrm{~cm}^{-3}[12]$ \\
Acceptor concentration $\left(N_{A}\right) \mathrm{C}-\mathrm{Si}$ & $7.6 \times 10^{17} \mathrm{~cm}^{-3}[12]$ \\
Electron diffusion $\left(D_{n}\right)$ a-Si:H & $40 \mathrm{~cm}^{2} / \mathrm{s}[7]$ \\
Hole diffusion $\left(D_{p}\right)$ a-Si:H & $10 \mathrm{~cm}^{2} / \mathrm{s}[7]$ \\
Electron diffusion $\left(D_{n}\right) \mathrm{C}-\mathrm{Si}$ & $800 \mathrm{~cm}^{2} / \mathrm{s}[8]$ \\
Hole diffusion $\left(D_{p}\right) \mathrm{C}-\mathrm{Si}$ & $200 \mathrm{~cm}^{2} / \mathrm{s}[8]$ \\
Ratio between charge and neutral $(c)$ & $50[9]$ \\
Electron mobility $\left(\mu_{n}\right)$ a-Si:H & $40 \mathrm{~cm}^{2} / \mathrm{V} . \mathrm{s}[7]$ \\
Hole mobility $\left(\mu_{p}\right)$ a-Si:H & $10 \mathrm{~cm}^{2} / \mathrm{V} . \mathrm{s}[7]$ \\
Electron mobility $\left(\mu_{n}\right) \mathrm{C}-\mathrm{Si}$ & $800 \mathrm{~cm}^{2} / \mathrm{V} . \mathrm{s}[7]$
\end{tabular}




\begin{tabular}{lr}
\hline \multicolumn{1}{c}{ Parameter } & \multicolumn{1}{c}{ Value } \\
\hline Hole mobility $\left(\mu_{p}\right) \mathrm{C}-\mathrm{Si}$ & $200 \mathrm{~cm}^{2} / \mathrm{V} . \mathrm{s}[7]$ \\
Electron life time $\left(\tau_{n}\right)$ & $2.5 \times 10^{-12} \mathrm{~s}[12]$ \\
Hole life time $\left(\tau_{p}\right)$ & $1 \times 10^{-11} \mathrm{~s}[12]$ \\
Minimum energy density in donor and acceptor $\left(g_{\text {min }}\right)$ & $10^{16} \mathrm{~cm}^{-3} \mathrm{eV}^{-1}[13]$ \\
Donor energy $\left(E_{D}\right)$ & $0.088 \mathrm{eV}[7]$ \\
Acceptor energy $\left(E_{A}\right)$ & $0.053 \mathrm{eV}[7]$ \\
Minimum energy of conduction band $\left(E_{m c}\right)$ & $0.65 \mathrm{eV}[7]$ \\
Gap energy in p-type $\left(E_{g}\right) \mu \mathrm{C}-\mathrm{Si}: \mathrm{H}$ & $1.88 \mathrm{eV} \mathrm{[14]}$ \\
Gap energy in i-type $\left(E_{g}\right) \mu \mathrm{C}-\mathrm{Si}: \mathrm{H}$ & $1.7 \mathrm{eV}[14]$ \\
Gap energy in n-type $\left(E_{g}\right) \mu \mathrm{C}-\mathrm{Si}: \mathrm{H}$ & $1.1 \mathrm{eV}[15]$ \\
Energy in the valence band $\left(E_{v}\right)$ & $0.045 \mathrm{eV}[4]$ \\
Cross-section of the catcher at thermal velocity $\left(v_{t h} \sigma_{N}\right)$ & $10^{16} \mathrm{~cm}^{-3} \mathrm{~s}^{-1}[7]$ \\
Mesh & 0.00115 \\
\hline
\end{tabular}

The microcrystal silicon films have been divided into 4 regions (Figure 1). The division of region in the microcrystal silicon films has been two types of boundary conditions, namely Dirichlet and Neumann. Dirichlet boundary conditions are using to describe the electric potential and charge carrier concentration. The charge carrier concentration device gives rise to the electric potential of the same magnitude as the outgoing voltage coupled with energy changes throughout the device. The electric potential and charge carrier concentration (electron-hole) are written in equations 4, 5, 6 [16].

$\psi=V_{A}+\frac{k T}{q} \ln \left(\frac{\frac{N}{2}+\sqrt{\left(\frac{N}{2}\right)^{2}+n_{i}^{2}}}{n_{i}}\right)$

$n=\frac{N}{2}+\sqrt{\left(\frac{N}{2}\right)^{2}+n_{i}{ }^{2}}$

$p=-\frac{N}{2}+\sqrt{\left(\frac{N}{2}\right)^{2}+n_{i}{ }^{2}}$

While the boundary region is not related to the conductor (metal), it can be explained using Neumann boundary conditions, as written in equations (7), (8), and (9) [16]

$\widehat{n} . E=0$

$\widehat{n} . J_{n}=0$

$\widehat{n} \cdot J_{p}=0$ 


\section{Results and Discussion}

The simulation obtained charge carrier distribution and current density-voltage (J-V) characteristics from solar cell devices based of hydrogenated microcrystal silicon $(\mu \mathrm{c}-\mathrm{Si}: \mathrm{H})$ on p-i-n junction with a thickness of $150 \AA$ / $5500 \AA$ / $300 \AA$ respectively. The result of the charge carrier distribution profile is shown in Figure 2 and Figure 3.

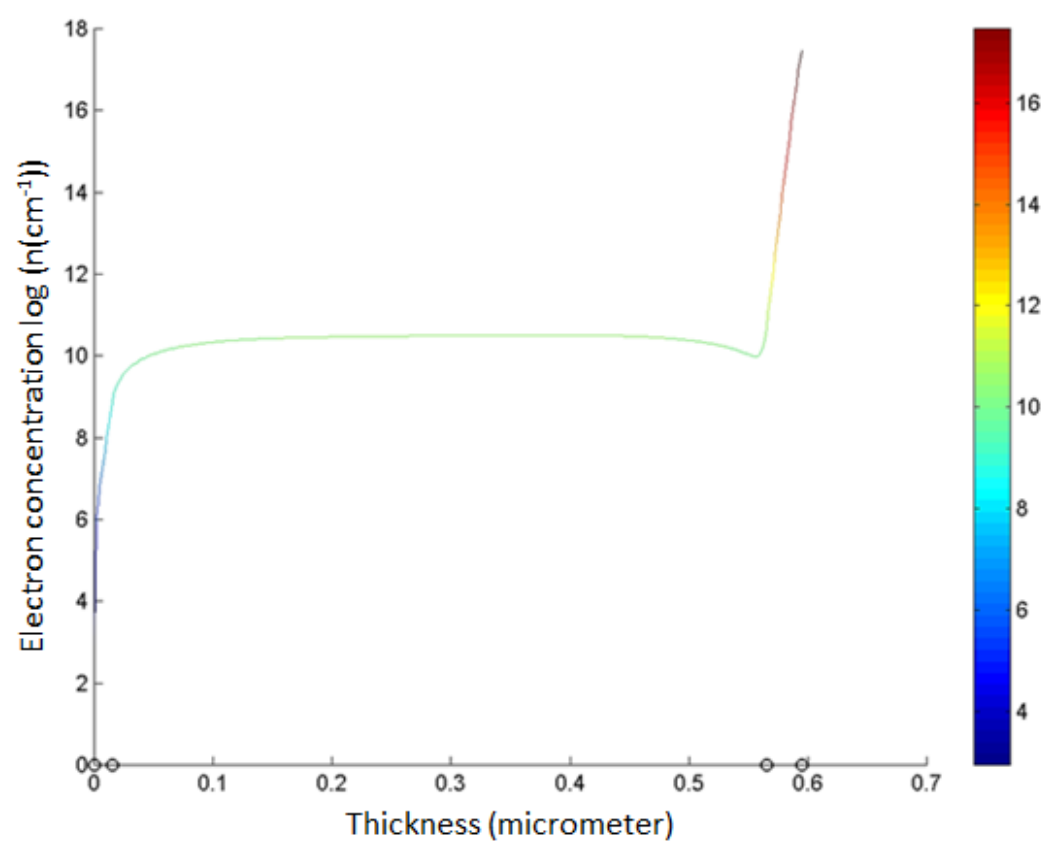

Figure 2. One dimensional simulation of the electron concentration profile of hydrogenated microcrystal silicon- ( $\mu \mathrm{c}-\mathrm{Si}: \mathrm{H})$ solar cell on p-i-n homojunction structure with a thickness of $150 \AA / 5500 \AA / 300 \AA$ and output voltage of 0 volts

In Figure 2, the profile of electron concentration performs that the lowest number of the electron concentration is at the end of the $p$-layer, indicated by a dark blue indicator located at $10^{4} \mathrm{~cm}^{-1}$. The concentration of electrons in the i-layer is relatively constant of $10^{11} \mathrm{~cm}^{-1}$ indicated by a green indicator. Meanwhile, the highest electron concentration is the maximum concentration of donor atoms located at the end of the n-layer connected to the metal contacts indicated by a deep red indicator of $10^{18} \mathrm{~cm}^{-1}$. 


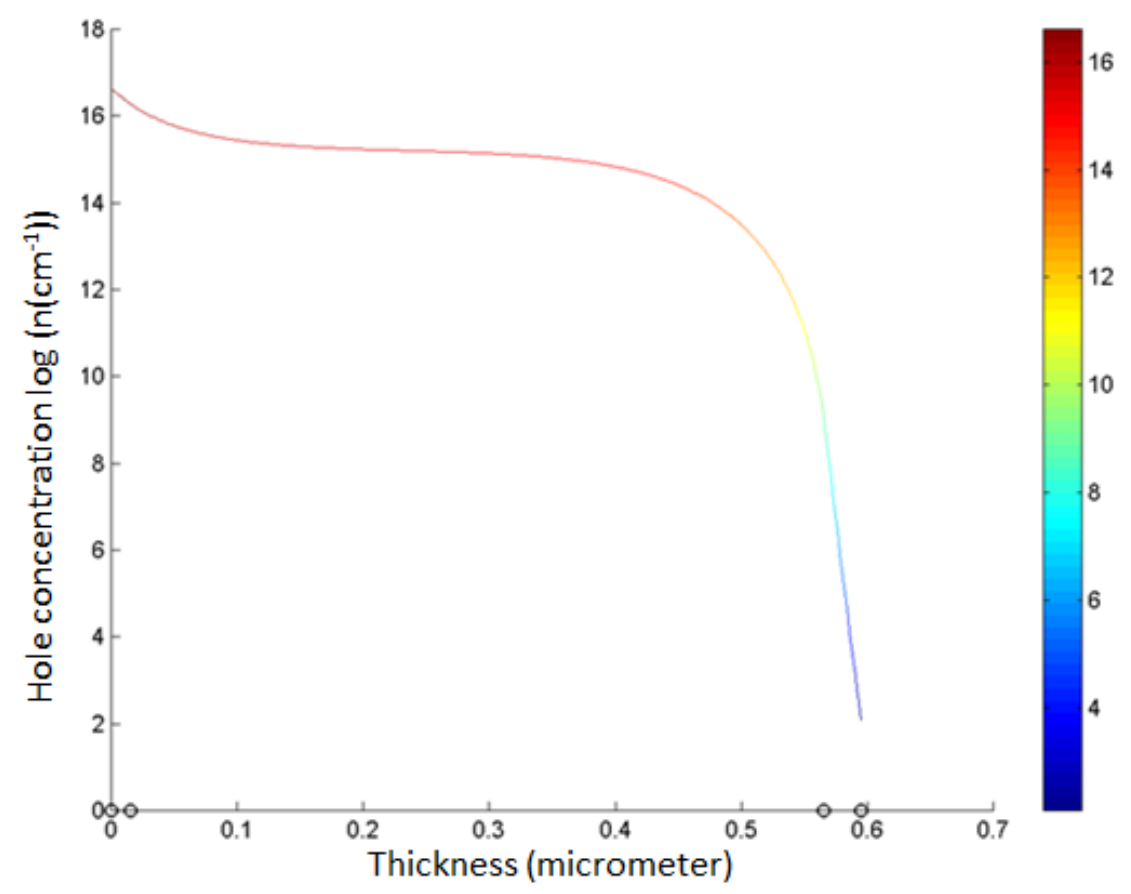

Figure 3. One dimensional simulation of the hole concentration profile of hydrogenated microcrystal silicon ( $\mu \mathrm{c}-\mathrm{Si}: \mathrm{H}$ ) solar cell devices on $\mathrm{p}$-i-n homojunction structure with a thickness of $150 \AA / 5500 \AA / 300 \AA$ and output voltage of 0 volts

In Figure 3, it can be obtained that the highest hole concentration in the p-layer is close to the anode indicated by a deep red indicator of $10^{18} \mathrm{~cm}^{-1}$. The highest hole concentration is the maximum concentration of the $\mathrm{N}$ acceptor atom. At i-layer, the concentration of the hole load carrier is relatively constant of $10^{12} \mathrm{~cm}^{-1}$. Then for the n-layer, there is a decrease drastically in hole concentration until it reaches the lowest hole concentration at the end of the n-layer of $10^{2} \mathrm{~cm}^{-1}$. The majority of electron concentrations in the n-layer, while the concentration of the majority of holes lies in the p-layer.

The distribution profile of the carrier concentration produced is further used to describe the current density-voltage $(\mathrm{J}-\mathrm{V})$ characteristics of solar cell devices. Figure 4 show the simulation results of current-voltage $(\mathrm{J}-\mathrm{V})$ characteristics of $\mu \mathrm{c}-\mathrm{Si}$ : $\mathrm{H}$ solar cell on $\mathrm{p}$-i-n junction with a coating thickness of $150 \AA / 5500 \AA / 300 \AA$ respectively. 


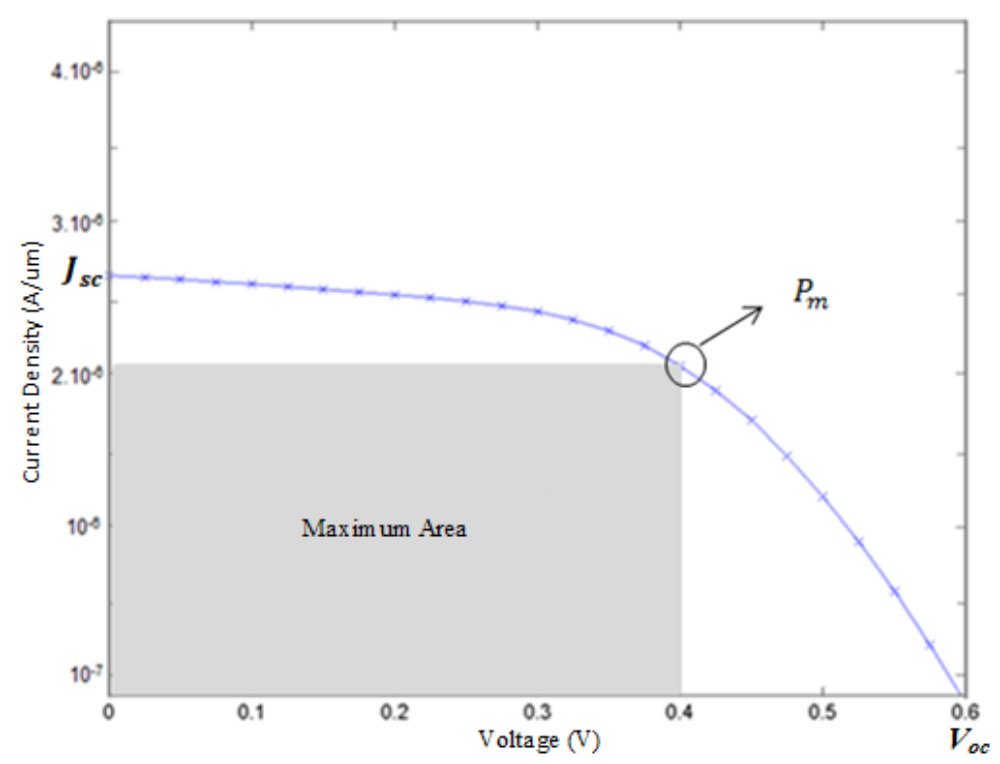

Figure 4. J-V characteristics curve of a $\mu \mathrm{c}-\mathrm{Si}$ : $\mathrm{H}$ solar cell devices on $\mathrm{p}-\mathrm{i}-\mathrm{n}$ homojunction structure with a thickness of $150 \AA / 5500 \AA / 300 \AA$, where the shaded area indicates the maximum area used in the calculation of device output power

Figure 4. indicates that the open-circuit voltage $(\mathrm{V})$ of the simulation result is 0.6 volts, and short circuit current $(\mathrm{J})$ of $26.4 \mathrm{~mA} / \mathrm{cm}$. A comparison of the current density-voltage $(\mathrm{J}-\mathrm{V})$ characteristics curve from the simulation results in this study, Klein's experiments [3], and Lin's simulations [4] is shown in Figure 5.

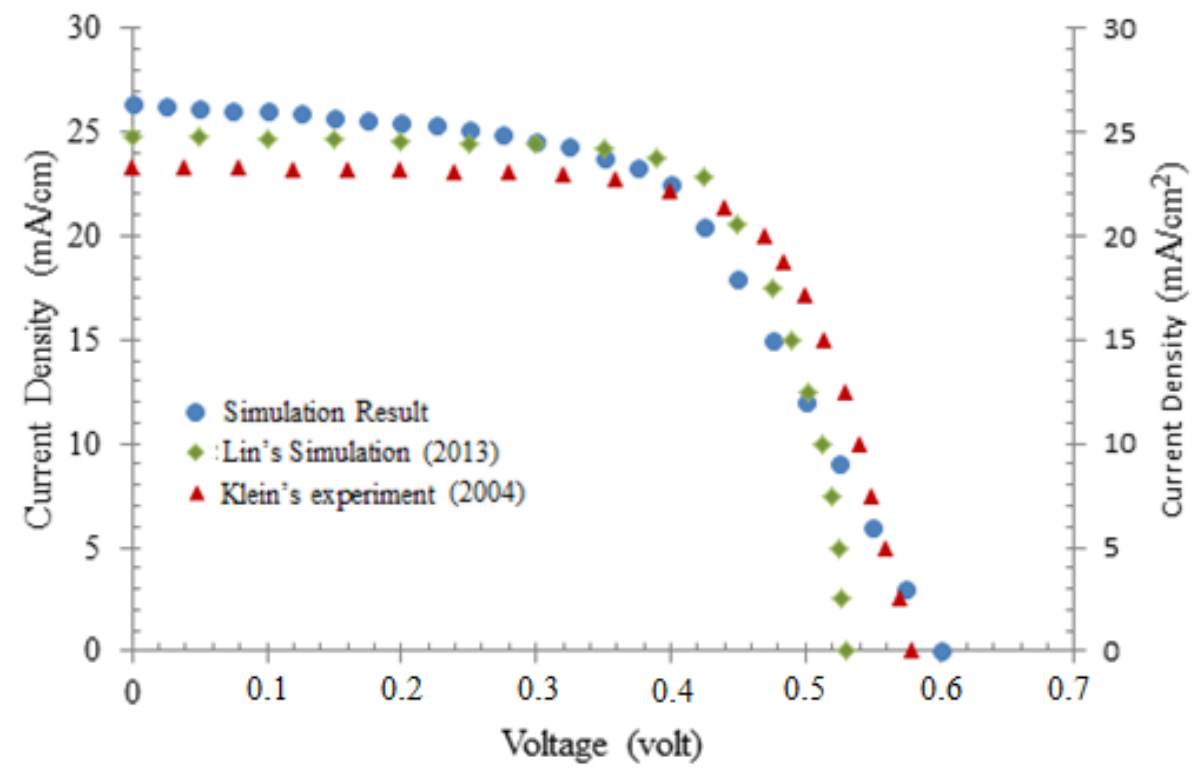

Figure 5. The current density-voltage $(\mathrm{J}-\mathrm{V})$ characteristics of hydrogenated microcrystal silicon $(\mu \mathrm{c}-\mathrm{Si}: \mathrm{H})$ solar cell by Lin's simulation, Klein's experiment, and simulation in this study 
The simulation of current density-voltage $(\mathrm{J}-\mathrm{V})$ characteristics curve of this study occurred changes in current tightness significantly not as sharp as Klein's experiments. The tight circuit of the Klein's experiment $(\mathrm{J}-\mathrm{V})$ was relatively stable for the current-density value at a voltage of 0 0.4 volts. While at a voltage of $0.4-0.58$ volts, the change in current tightness decreases drastically. The change in the current-density is insignificant.

The result of current density-voltage $(\mathrm{J}-\mathrm{V})$ characteristics curve on this simulation is not as sharp as the Lin's simulation and decreases in current value significantly. Lin's simulation current density-voltage $(\mathrm{J}-\mathrm{V})$ characteristics curve is relatively stable for current tight values at voltages of $0-0.4$ volts. While at a voltage of $0.4-0.53$ volts, the change in current tightness decreases drastically.

The addition of equations for crystal-structured semiconductor materials in an amorphous structure, semiconductor materials can affect the tight current density-voltage (J-V) characteristics. Figure 6. indicated the difference in the results of the calculation of electrical current-density between the modeling of amorphous and microcrystal materials.

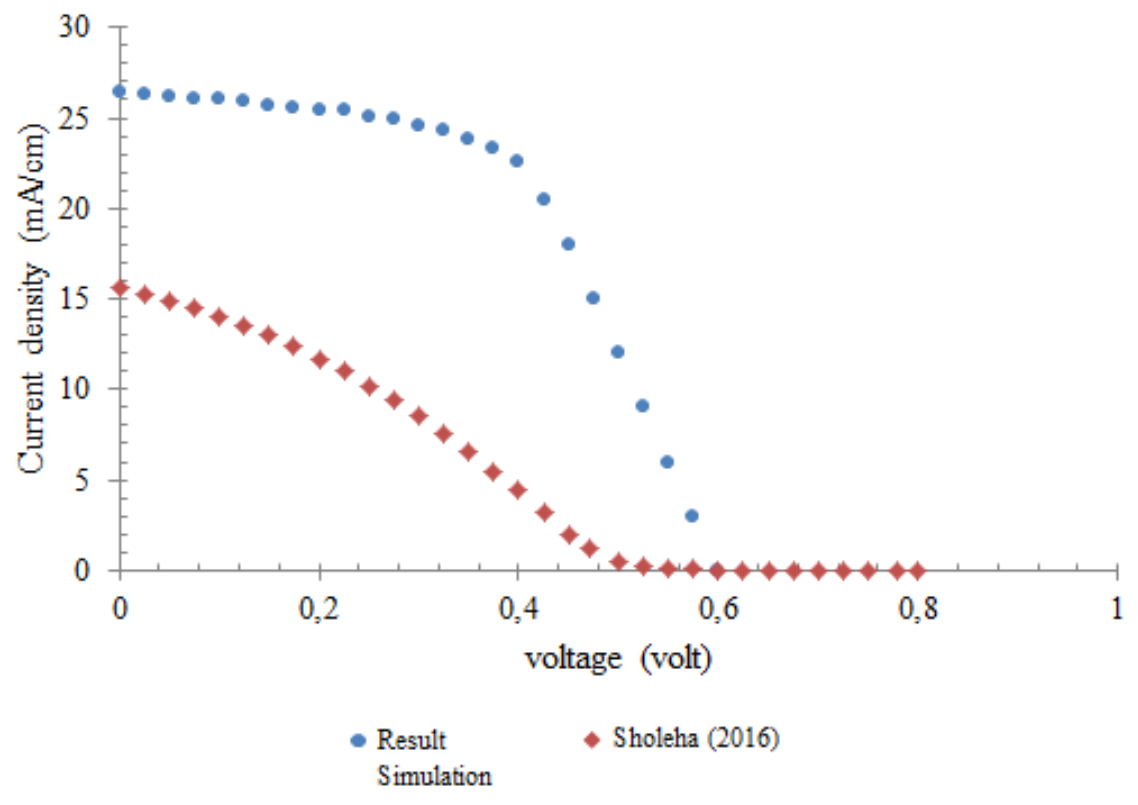

Figure 6. The current density-voltage $(\mathrm{J}-\mathrm{V})$ characteristics curve of hydrogenated microcrystal silicon ( $\mu \mathrm{c}-\mathrm{Si}: \mathrm{H})$ solar cell conducted in simulation (in this study) and Sholeha simulation using hydrogenated amorphous silicon (a-Si: $\mathrm{H})$ solar cell

The simulation results by Sholeha using a hydrogenated amorphous silicon device (a-Si: $\mathrm{H}$ ) solar cell in the $\mathrm{p}$ and $\mathrm{i}$ layers and using a hydrogenated microcrystal silicon solar cell device in the n-layer is resulting circuit open voltage of 0.8 volts and a short circuit current of 15.61 
$\mathrm{mA} / \mathrm{cm}$ [6]. While the current density in this study of $26.4 \mathrm{~mA} / \mathrm{cm}$. By adding semiconductor equations for crystal materials to semiconductor equations for amorphous materials, it can increase the electrical current-density devices by $69 \%$.

The energy conversion efficiency is a reference to the magnitude of the performance of solar cell devices. The amount of calculation of conversion efficiency of hydrogenated microcrystal silicon ( $\mu \mathrm{c}-\mathrm{Si}: \mathrm{H}$ ) solar cell on p-i-n homojunction structure obtained in this study of $9.02 \%$.

\section{Conclusions}

The conclusion of this study that the charge carrier distribution profile of hydrogenated microcrystal silicon ( $\mu \mathrm{c}-\mathrm{Si}: \mathrm{H}$ ) solar cell devices on $\mathrm{p}-\mathrm{i}-\mathrm{n}$ homojunction structure with a thickness of $150 \AA / 5500 \AA / 300 \AA$ is the highest charger carrier concentration of electron in the n-layer of $10^{18} \mathrm{~cm}^{-1}$ and the highest charger carrier concentration of hole in the p-layer of $10^{18} \mathrm{~cm}^{-1}$. The current density-voltage $(\mathrm{J}-\mathrm{V})$ characteristics curve obtained an open-circuit voltage up to 0.6 volts. While the close the short circuit current of $26.4 \mathrm{~mA} / \mathrm{cm}$. In addition, the energy conversion efficiency of $9.02 \%$ with a fill factor of 0.569 .

\section{References}

[1] S.V. Litvinenko, A. V. Kozinetz, dan V. A. Skryshevsky, 2015, Concept of Transducer on a Base of Modified p-n Junction Solar Cell. Institute of High Technologies, Science Direct, Kyiv 01601: Ukraine.

[2] S. Veprek, dan V. Marecek. 1968, The Preparation of Thin Layers of Ge and Si by Chemical Hydrogen Plasma Transport, Solid State Electron, volume 11, page 683-684.

[3] S. Klein, T. Repmann, dan T. Brammer, 2004, Microcrystalline Silicon Films and Solar Cells Deposited by PECVD and HWCVD, Solar Energy, volume 77, issue 6, page 893908.

[4] C. H. Lin, T. H. Wen, dan H. T. Cheng, 2013, Single Grain Boundary Modeling and Design of Microcrystalline Si Solar Cells, Materials, volume 6, page 291- 298.

[5] Y. Herawati, 2014, The Effect Of Thickness I-Layer on Calculation of Current-Voltage Characteristics Solar Cells PIN Using Finite Element Method, Skripsi, Jember: FMIPA University of Jember.

[6] A.D. Sholeha, 2016, Investigation of The Charge Carrier Diffusion Coefficient in Simulation of Energy Conversion Efficiency Solar Cell Based on a-Si:H, Skripsi, Jember: FMIPA, Universitas Jember.

[7] I. Usman, 2006, The Growth of Thin Films of Hydrogenated Amorphous Silicon Using HWC-VHF-PECVD Technique and the Application of Solar Cell. Unpublished. Dissertation. Bandung: ITB. 
[8] E. Danielsson, 2000, FEMLAB Model Library for Semiconductor Device Model, Stockholm: The Royal Institute of Institute.

[9] E. Purwandari, and T. Winata, 2013, Efficiency Calculation Analysis of A-Si:H Solar Cells for Determination of Optimum Filament Temperature in Material Deposition, Jurnal IImu Dasar, volume 14, no. 1, page 29-32

[10] M.A. Nigro, F. Cantore , F.G. Della Corte, C. Summonte, 2003, Amorphous Silicon Thin Film for All-Optical Micro Modulator, Proceeding of SPIE. 5116.

[11] D. Corrine, 2003. Thin Film Microcrystalline Silicon Layers and Solar Cells: Microstructure and Electrical Performances, Thesis, Swiss : Institut de Microtechnique.

[12] C.V. Sanchez, 2001, Thin Film Nanocrystalline Silicon Solar Cell By Hot-Wire CVD. Barcelona: Department De Fisica Aplicada I Optica.

[13] K. Takahashi, and M. Konagai, 1986, Amorphous Silicon Solar Cells, London: North Oxford Academic Pub. Ltd.

[14] D.M. Jasruddin, and A. Momang, 2009. Development of Hydrogenated Amorphous Silicon Solar Cell p-i-n in Double PECVD Reactor. Physics Application Journal, volume 5, no.1, page 14-21.

[15] S. Schicho, 2010, Amorphous and Microcrystalline Silicon Applied in Very Thin Tandem Solar Cells, Germany: Institut für Energie- und Klimaforschung.

[16] M. Hack, and M. Shur, 1985, Physics of Amorphous Silicon Alloy p-i-n Solar Cells, Journal of Applied Physics, volume 58, no. 2, page 997-1020. 